secretions is it contained: whether those of the lungs, skin, stomach, bowels, or kidney? In which is it most abundant and most active? And in which others is it certainly not contained?

The majority of continental experiments appear to show that the intestinal evacuations are the seat or source of the poison, while the blood is not. In this country authors almost inva. riably adopt the evacuation theory, for it is not yet, I think, conclusively proved. In all experiments up to the present day there have been fallacies connected with the mode of conducting the investigation, which render it impossible for us to eliminate a single irrefragable fact, save the general one that cholera has been produced in animals by one or more of the excretions of the human subject. Which one, or which two or three excretions, remain to be fully determined. In my own experiments it was the fomites which appeared to be the immediate cause or source of the disease in the dog and cat. But the same animals had been previously subjected to the influence of the evacuations from the stomach and intestines, the blood, and the urine of human cholera patients. The only apparent result of this influence was diarrhoa, which I regarded at the time as nonspecific, but which, with modern views, may be considered as pre-choleraic. In no case did it progress into cholera, but I held then, and still hold, that at least this diarrhcea constituted a powerful predisposing cause of cholera. My immediate object here, however, is to show that in so far as other sources of disease were not rigidly excluded, it can only as yet be considered a fair inference from the whole facts of the case, that the fomites were the only, or prime choleraizing agents-an inference that may be fairly disputed on valid grounds.

7. In what stage of the disease in man is the communicable poison in his secretions or excretions in largest amount and in most active quality?

8. In what condition of freshness or decomposition, concentration or dilution, solidity or fluidity, or otherwise, of the excretions in man is the communicable poison most dangerous ?

9. Is the medium of conveyance of the poison, or is the poison itself, solid or gaseous, fixed or volatile? Is it impal. pable-inappreciable to optical examination? Is it purely chemical, and of the nature of a gas ; or is it of the nature of molecular matter-organic or inorganic-in a state of extreme division? Is it, or is it allied to, the "germinal matter" of Beale, and appreciable to high microscopic powers? Is what appears to be the poisonous essence simply a medium for the conveyance of an inscrutable entity still destined to elude all our powers of examination or analysis?

10. What is the period of incubation in different individuals, species, or genera?

11. On what surfaces of the body of animals does the poison primarily and secondarily take effect? Is it exclusively the pulmonary or intestinal mucous membrane, or skin-all, or which? In certain series of experiments (fomites) the result would appear to have been produced by the action of a volatile poison on the pulmonary surface-the poison seems to have been inspired; while in certain others (evacuations) a solid or fluid poison apparently acted directly on the intestinal tract-the poison was swallowed. The inference is, in the first case, that the poison is gaseous; in the second, that it is solid or fluid. But eren in the first case, supposing it proved that fomites do communicate the disease, the poison or its medium may con. sist of minute microscopic molecules sufficiently light to float freely in atmospheric currents and be inspired; while in the second case it may be a volatile or gaseous matter that is the source of propagation. Data are yet insufficient to determine with precision any of these points.

12. Is cholera in animals transmissible only between individuals of the same species; or between different species, genera, and classes: between domesticated and wild animals of the same or different species, genus, or class : between animals and man? This inquiry opens up a wide and quite novel field-one on which, unfortunately, I had no opportunity of at all entering. But in so far as in cholera naturally acquiredin the so-called epizootic cholera-such intercommunication exists, as it does also in other diseases, it is at least probable that it will be found to occur as regards cholera artificially produced.

13. Modes or Forms of Experimentation.-In order to the determination of the doubtful points hereinbefore referred to, it is, inter alia, desirable that separate subjects of experiment should be brought under the exclusive influence of the (1) breath, (2) sweat, (3) stomach ejecta, and (4) intestinal evacuations of cholera patients; that in the first two, by filtra. tion of the effluvia or otherwise, endeavour should be made to determine how far the poison is gaseous, fluid or solid; that in the two latter, equal endeavour should be made to determine whether the volatile emanations are not sufficiently poisonous to communicate the disease; that in the case of the evacuations various experiments should be made in evaporating or concentrating, reducing to the solid and dry state, so as to determine so far the exact medium of communication, and to ascertain the effects of concentration or dilution, dryness or fluidity. Inhalation, swallowing, injection, should all be tried in legitimate forms; bearing in mind always the sources of fallacy attachable to the form or instrument of experiment. Of these, most has already been done apparently in the way of injection and swallowing, least in that of inhalation, which appears to me to be the most promising direction of the three. It is necessary to take especial care that in experiments with gaseous matter there should be no contamination with light molecular aerial matter-of the nature, e.g., of germinal matter, from dried evacuations or excretions, - if such exclusion is, indeed, possible or practicable.

14. In connexion with cholera artificially produced, cholera epizootics (cholera naturally acquired in animals) merit a careful study. If it be proved that such affections are cholera, and not merely choleroid, their study in connexion with choleraization in animals cannot fail to bear most intimately on the study of cholera in man.

These are but a few illustrations of the points that appear to me to possess special interest at the present time in connexion with choleraization. For further details I would refer the reader to the various papers undernoted, which either contain records of my own experiments, and references to those of $\mathrm{my}$ predecessors, or develop more fully my views as to the scope and direction of future experiment. The special investigations recently made under the auspices of the Cattle Plague Commissioners are also pro tanto models of what is required in an experimental inquiry as to the nature of cholera.

Bibliographical References.-1. "Experiments on the Communicability of Cholera to the Lower Animals." Edinburgh Medical and Surgical Journal, April and October, 1854. 2. "Experimentation on the Transmissibility of Cholera to the Lower Animals." Association Medical Journal, Dec. 15th, 1854, p. 1113. 3. "On the Transmission of Diseases between Man and the Lower Animals." Edinburgh Veterinary Review and Annals of Comparative Pathology, July, 1858. 4. "Suggestions for Observations on the Influence of Cholera on the Lower Animals." Edinburgh Medical Journal, July, 1857. 5. "On Cholera Epizootics." Association Medical Journal Dec. 15th, 1854, pp. 1110 and 1111. 6. "On the Artificial and Accidental Communicability of Cholera to the Lower Animals." Association Medical Joumal, Sept. 15th, 1854, p. 836. 7. "The Cattle Plague in some of its Aspects." The Lancet, May 16th, 1857.

Gilgal, Perth, November, 1866.

\section{CASES OF GUNSHOT WOUNDS OCCURRING DURING THE LATE WAR IN GERMANY.}

\section{B y F. H. L O V E L L, Es Q.}

Gunshot Wound of the Stomach.

J. K_- aged twenty-five, a married soldier from the 4th Austrian Infantry Regiment; was wounded at the battle here (Tratenan̂) on the 27th June, late in the day. He states that while the Prussians were retreating on the evening of the 27 th he received his wound and fell, and in the course of the night he was brought down here into the town. After the Prussians took the town on the following day he was put into this hospital, and has been here ever since.

First, on looking at this man's coat, there are two holes in it, situated about the waist: the one on the left is cleanly cut, about the size of a sixpenny-piece; the one on the right side is more than twice that size, and has ragged edges. On examining him, there is a gunshot wound between the seventh and eighth ribs on the left side, where the ball entered; and a corresponding one between the sixth and seventh ribs on the right side, where the ball emerged, passing nearly transversely across the ensiform cartilage. The wound of exit is quite half as large again as the wound of entrance. The one on the left side is precisely in a line with the left nipple; the one on the right is an inch nearer the sternum. The two wounds are five inches 
apart from each other. After he was shot he says he did not feel as if he were much hurt; he did not faint, nor did he vomit at that time. On the following day he romited, and this lasted for several hours, but he cannot say whether there was any blood in the matters vomited. He remained quiet all this day, and the following day (29th) he was put into hospital. The wounds were dressed with charpie, a binder was put round his body, and he was put to bed. It should be added that he had had nothing to eat or drink since seven o'clock on the morning of the battle, and he fell about seren in the erening. The last food he had were some plums and a little wine. When the wounds were dressed on the 30 th, he says he noticed some thin dark fluid bubble out of the wound, as with gas. He was not sick on that day, nor had he much pain then or since, and he considered himself but slightly wounded.

Aug. 15th. - He has been kept quiet in bed ever since the 30 th of June; has had a liberal allowance of food, wine, and cigars; and he had no bad symptoms, excepting occusional vomiting of his food, and the escape of gas through the wound, generally about once a day. His general health is not very much impaired. The exit wound has healed, and the entrance wound has also healed, excepting a small aperture in its centre, through which there is a thin yellowish discharge, with an acid smell, but certainly not fecular, and the occasional escape of gas. A probe passed through this aperture takes a direction upwards towards the posterior border of the left axilla; and when introduced to the extent of five inches, its further passage is arrested by a soft yielding substance. By making pressure over the stomach, three drachms of the discharge were collected to-day in a small cup: its colour is a pale yellow; it is thin, and generally slightly puriform; it has an acid smell, but none of fæces; it gives an acid reaction to litmus paper. To-day, by way of experiment, he was given first an alkaline draught to drink, and immediately after this an acid one, and on taking the probe out of the wound there was a distinct escape of gas from it. He gets up now, takes his food well, and his bodily functions are regular.

26th.-His health is improving, and he takes his food well. He still occasionally vomits, and there is still an escape of gas through the fistula, generally after meals; the discharge from it is certainly less than it was.

Convalescent.

\section{Gunshot Wound followed by a Gall-Fistula; Death from Pycemia.}

P. L__ _ aged thirty-three, a Pole, wounded at Königgrätz on the 3rd July, and sent here from Pardubitz on the 10th. He was struck by a ball just below the cartilage of the last rib on the right side. From the appearance of his coat, the ball must have struck him in a very slanting direction from left to right, as it has made one ragged tear in it, four inches long. He did not even know that he was wounded till after the battle.

On examining him, there is a wound about the size of a crown-piece situated four inches to the right of the umbilicus and an inch below the cartilage of the last rib. The wound is discharging slightly, a rather offensive dark discharge; the edges have a healthy appearance, but the centre of the wound is occupied by a slough the size of a half-crown, which is separating very slowly from the healthy parts. He does not suffer much pain, but his health is considerably damaged. He takes his food well; he is kept in bed; and the wound is dressed with charpie and chloride of lime.

Aug. 1st. - The slough separated yesterday, and has left a deep granulating wound. The close resemblance of the stains on his shirt to those of bile drew attention to-day to a small aperture in the middle of the wound, through which a probe can be passed for four inches into the abdominal carity. By pressing over the liver on either side of the wound, a thick yellowish-brown discharge is seen oozing through this aperture, and to-day we collected about two drachms of this, which on chemical analysis was proved to be bile. He takes his food well, and does not complain of pain. $\mathrm{He}$ has an opiate at night, as he cannot sleep well without it. Bodily functions regular.

7 th. - On the 5th he was seized with shivering, and the rigors now continued two or three times daily. He has lost his appetite; his face is dusky; pulse varies, generally about 90, soft ; tongue is red and dry. He has got diarrhoea to-day; motions dark, loose, and very offensive. The wound has broken open again round the fistula.

9th.-He became worse, in spite of quinine, wine, \&c., and he died last night.

A post-mortem examination was made, and a large abscess was found occupying the lower and part of the middle lobe of the right lung; this lung was firmly adherent to the walls of the chest. The left lung was healthy, as indeed were all the other organs; but the liver was somewhat large, and showed the results of recent inflammation on its surface, though its substance was healthy. The gall-bladder was firmly adherent to the abdominal walls, and through this adhesion a probe could be passed from without through the fistula into its interior. A piece of eloth was found in it; at first it was doubtful what this was, but after washing it there remained no doubt. This circumstance made one almost think it was possible that the ball had lodged, but every search was made for it in vain. The peritoneum showed the results of recent inflammation only around the seat of injury.

\section{Gunshot Wound of Pelvis, folloved by Crinary Fistula;}

Recocery.

P. T_- aged twenty, a Tenetian, in the 12th Austrian Infantry Regiment. He was wounded at Küniggrätz on July $3 \mathrm{rd}$, late in the day, and remained on the field twenty-four hours after the battle; was sent to Pardubitz, where he remained a week; and arrived here on the $10 \mathrm{th}$. The ball struck him over the left tuber ischii, and emerged through the right groin.

From the 3 rd to the 18 th he did not pass any urine by the natural way, it nearly all came through the wound in the nates; on the 18th he first passed a little by the penis, and since then he has been able to pass it when called upon. In addition to this, he lost all power over the sphincter ani till the 15th, since which date he has been gradually regaining its use.

July 25th. - Since he has been here, little has been done for him beyond dressing the wounds twice daily and attending to his bowels \&c. He takes his food well, and has a good allowance of tobacco; also a quarter of a grain of morphia every night. The wounds now present a healthy appearance. In this case the exit wound, contrary to the generality of cases now here, is in a more advanced stage of healing than the entrance wound. No doubt this is owing to the much freer discharge of urine through this wound. About a teacupful now passes by this wound in the twenty-four hours. The discharge from both wounds is lessening, and presents a healthy appearance. He can now hold his motions, and defecation is not attended with pain. There is nothing abnormal to be felt by the finger in the rectum. He has got the bullet as it fell out of the wound. It is from a needle-gun, but is much altered in shape: it is now flattened, and has one rather sharp angle; but it is entire. From the appearance of his clothes, there wust have been considerable hemorrhage at the time of the accident, but there has not been any since.

Aug. 5th. - The wounds have now both healed, all but a very small opening in the cicatrix of the entrance wound, through which a few drops of urine flow occasionally when he walks about. He passes his urine freely, and without pain. His motions are natural, and passed without pain, and he has quite recovered the use of the sphincter muscle.

15th. - Within the last few days the fistulous opening in the nates has healed of its own accord. He goes about now well.

\section{Gunshot Wound of Pelvis: Ball lodged; Urinary Fistula;} Recovery.

F. $\mathrm{N}-$, aged twenty-five, a Hungarian soldier, in the 7 th Austrian Infantry Regiment, wounded at Königgrätz on the $3 \mathrm{rd}$, and sent here with many other wounded prisoners on the 10th of July.

This is in some respects a very similar case to the preceding. The ball struck the man, while he was standing and loading, over the right tuber ischii, and lodged. In this case also there was considerable hemorrhage at the time of the accident. For the first ten days all the urine came away through the wound; on the eleventh day he passed a little through the penis, and since then he has passed it regularly. There was no paralysis of the sphincter ani, nor has he had a single bad symptom but the urinary fistula.

July 25th.-He is still in bed, takes his food well, and his bodily functions are regular. The wound discharges slightly, and the discharge has still a urinary smell. A probe can be passed through the wound to the extent of four inches, when its further course is arrested by a firm elastic substance. The ball bas been looked for in every conceivable direction, but as yet it cannot be found. Thinking it might possibly have lodged in the bladier, he was sounded to-day, but it is not there.

Aug. 2nd.-The wound in the buttock has healed, and he 
passes his urine freely, and without pain. No urine has come through the wound now for several days. During the last few days he has been complaining of pain in the inside of the left thigh; and to-day, there being distinct fluctuation, a deep incision was made into it, and a quantity of healthy pus was evacuated. We certainly expected to find the bullet here, but all search was made for it in vain. His health is good.

15th. - The abscess has healed, and he is convalescent; but the ball has not yet been found.

Gunshot Wound through the Riglet Thigh, carrying away the Scrotunt and Testes; Recovery.

K. M- , aged twenty, an Austrian jäger, who was wounded at $K$ öniggraitz on the 3 rd, was sent to Pardubitz with other prisoners, and arrived here on the 12th of July.

The ball struck him below and just behind the trochanter major of the right femur, and emerged on the inside of the right groin ; then, carrying away both testes with most of the scrotum, it grazed the left groin, and there left him. A good idea of the course this ball took may be formed by simply looking at the man's trousers; the greater part of both the pockets in them are carried away. There was no external hremorrhage at the time of the accident, and there has been none since. A probe introduced into the entrance wound strikes against the posterior edge of the trochanter major, and passing beneath this, it can be made to emerge in the groin. He is kept quiet in bed, and the wounds are only dressed with charpie. He takes his food well, and his bodily functions are regular. The wounds are both discharging slightly, but the discharge is healthy. Several small pieces of linen have come away through the exit wound within the last week. The entrance wound is in a more advanced stage of healing than the exit. The remaining portion of scrotum has also healed, and is now contracted round the root of the penis. The grazing over the left groin is still distinctly visible as a brown puckered cicatrix abont three inches in length.

Aug. 15th. - Both wounds have healed, and he is quite well. Karthaus, Aug. 1866.

\section{THE REGULATORS OF THE GLOTTIS.}

\section{By GEO. DUNCAN GIBB, M.D., ASSISTANT-PHYSICIAN TO WESTMINSTER HOSPITAL,}

THE revelations of the laryngoscope have clearly demonstrated the necessity of discarding many of the expressionsanatomical and pathological-which have been hitherto commonly employed concerning the larynx. The propriety of this cannot be doubted; and in a little while certain terms will be recognised as distinctively indicating particular lesions, parts, or actions. I believe I was the first person to show that the expression "cedema of the glottis" was an anomaly and a misnomer, and that it should be replaced by the more rational term "cedema of the larynx," subdivided into the supraglottic form (the ordinary and old cedema of the glottis) and the more rare yet by no means infrequent subglottic form. Into this, however, I must not at present enter, but will say a few words upon the false vocal cords.

We know that phonation, or sound of any kind entitled to the term rocalisation, can only be produced through the agency of the vocal cords, now so well known that it would be superfluous to dilate upon them; and what have hitherto been called the false, in contradistinction to the true vocal cords, have nothing whatever to do with phonation, beyond any modifying influence they may possess in modulating the tones of the voice. They possess no right nor title to be called vocal cords at all; and, with the desire of co-operating with my brethren of the English school of medicine, I shall henceforth discard the expression "false vocal cords," and also the terms (used in anatomy) "superior and inferior ligaments of the glottis."

The question then arises, What name shall be given to the false vocal cords? This can be best answered by considering their nature, and the particular function which they perform. They are formed by the upper dirision of the triceps laryngea muscle-a muscle capahle of division into three bundles of fibres, as marle out by Battaille, whose views, with corroborative reflections. were published in THE LArceT of Oct. 15th, $186 \pm$, in a paper by myself, on the various forms assumed by the glottis.
These remarkable muscles, corered by folds of mucous membrane of a delicate rose-pink colour, line the lateral boundaries of the larynx, and extend in an antero-posterior direction from near the angle of the thyroid cartilage, close to the root of the epiglottis, to the arytenoid cartilages. The ventricles are fissures or receptacles in these muscles, but the latter do not in any possible manner constitute bands to the ventricles, as in. deed any good anatomist must be aware. What then is their true signification? In plain words, they act the part of regulators of the glottis in the fullest sense: without their influence the glottis cannot open nor shut, nor can vibration necessary to the act of phonation occur. In deglutition, their influence is exerted firstly to close the glottis, and then to throw their protecting influence over it by meeting together to receive the impression and weight of the epiglottis with its sliding bolus. Let the fact be reasoned in erery possible way, the only conclusion to be arrived at is that the triceps laryngea-the thyro-arytenoid muscle-the heretofore false vocal cord-is a regulator of the glottis. If this then is undeniable, let them be called regulators of the glottis, a term more distinctive and expressive than any other, and moreover one that conveys to the mind of the student their actual meaning, and one certainly more euphonious than false vocal cords, or even thyroary-regulators, which some of our modern innovators might. be disposed to call them.

Bryanston-street, Portman-square, Nov. 1866.

\section{Ag iflitror}

OE THE PRACTICE OF

\section{MEDICINE AND SURGERY IN THE}

\section{HOSPITALS OF LONDON.}

Nulla autem est alia pro certo noscendi via, nisi quamplurimas et morborum. et dissectionum historias, tum aliorum, tum proprias collectas habere, et inter se comparare.-MorgagNI De Sed. et Caus. Morb., lib. iv. Procemium.

\section{ST. GEORGE'S HOSPITAL.}

STRAYGULATED CONGENITAL INGUINAL HERNIA; OPERATION ; RECOVERY.

(Under the care of Mr. Prescotr HeweTt.)

THE interest of the following case lies especially in the anatomical formation of the hernia. It was a good example of rupture into the vaginal process of the peritoneum-a form which it is important to distinguish from the ordinary kind of inguino-scrotal hernia. As will be seen, the occurrence of the hernia was characteristically sudden. A young man, previously healthy, finds after exertion a tumour in his scrotum. There is no gradual process of development, such as is observed in the ordinary inguino-scrotal rupture.

Mr. Birkett, in the article "Hernia" (Holmes's System of Surgery), remarks of these cases that the "tumour projects in a remarkable manner from the external outlet of the inguinal canal : directly the rupture escapes from the embrace of the external abdominal ring, the form is more globular and rounded in comparison with the pyriform outline of the hernia of slow formation in adult life." In the case before us Mr. Hewett lost no time in operating. He remarked that in these instances the stricture is so tight that severe mischief is occasioned with more than usual rapidity, unless the gut be quickly liberated. It is worth noticing, that the taxis is much less frequently successful in these cases than in the ordinary ingnino-scrotal hernia in which the sac is slowly formed. $\mathbf{M r}$. Birkett shows that of 57 cases collected at Guy's Hospital in which a cutting operation was required to liberate a strangulated hernia, 33 belonged to the class of which we are writing, and 24 were of the old slowly-forming variety. Again : of 129 cases of oblique inguinal hernia, 59 had traversed the canal of the vaginal process of the peritoneum, and 70 belonged to the old inguino-scrotal variety. Of the former kind, 33 per cent. required a cutting operation; of the latter, but 24 per cent.

We are indebted to Mr. E. C. Ring, surgical registrar, for notes of the case.

W. A-, aged nineteen, previously free from any signs of 